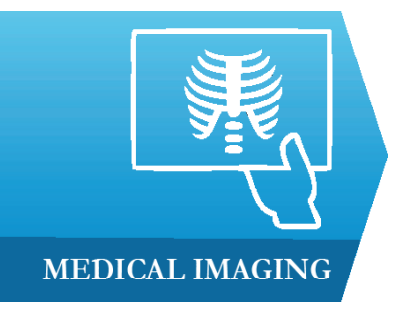

1) Department of Anatomy, Democritus University of Thrace Medical School, Alexandroupolis, Greece

2) Department of Neurosurgery, Democritus University of Thrace Medical School, University Hospital of Alexandroupolis, Alexandroupolis, Greece

3) Department of Radiology, Democritus University of Thrace Medical School, University Hospital of Alexandroupolis, Alexandroupolis, Greece

4) Department of Medical Physics, Imaging and Telemedicine, Democritus University of Thrace Medical School, Alexandroupolis, Greece

5) Aristotle University of Thessaloniki School of Mathematics, Thessaloniki, Greece.

DOI: $10.15386 / \mathrm{mpr}-2004$

Manuscript received: 21.12 .2020

Accepted: 26.01.2021

Address for correspondence:

theobirbilis@yahoo.com

This work is licensed under a Creative Commons Attribution-NonCommercialNoDerivatives 4.0 International License

\title{
Volumetric data of normal nucleus accumbens from magnetic resonance imaging scans
}

\author{
Theodosios Birbilis ${ }^{1,2}$, Achilleas Siozopoulos ${ }^{1}$, Aliki Fiska ${ }^{1}$, \\ Savas Deftereos ${ }^{3}$, Eleni Kaldoudi ${ }^{4}$, Vassilios Karagiannis ${ }^{5}$, \\ Vassilios Thomaidis ${ }^{1}$
}

\begin{abstract}
Backgrounds and aims. The nucleus accumbens $(\mathrm{AcN})$ belongs to the ventral striatum and it is involved in several neuropsychiatric disorders. In contrast to other subcortical structures, the number of morphometric studies that concern the healthy nucleus is limited. This study aims to investigate the normal volumetric data of the AcN as derived from a large number of manually segmented magnetic resonance imaging (MRI) scans.

Methods. The measurements were performed in 106 MRI scans of healthy adults. The resulting volumes have been analyzed for differences related to hemisphere, sex and age.

Results. The mean AcN volume was estimated at $473.3 \mathrm{~mm}^{3}(\mathrm{SD}= \pm 106.8)$. A slight interhemispheric difference in favor of the left side was found, the value of which was, however, within the limits of the method error. There were no sexual dimorphism signs concerning both the raw and the normalized volumes. A negative correlation between volumes and age was observed only in males.

Conclusions. The study provides normal volumetric data of the AcN, useful in the conduct of comparative imaging and post-mortem studies in pathological conditions.
\end{abstract}

Keywords: nucleus accumbens, ventral striatum, Magnetic Resonance Imaging, sex characteristics

\section{Introduction}

The nucleus accumbens $(\mathrm{AcN})$, which owes its name to Ziehem $\mathrm{T}$. (1904) [1], belongs to the basal ganglia and, more specifically, to the ventral striatum. It is located in the basal forebrain, together with the ventral pallidum, the olfactory tubercle, the basal nucleus of Meynert and part of the extended amygdala [2]. It continues dorsally with the putamen $(\mathrm{Pu})$ and the head of the caudate nucleus $(\mathrm{CdN})$ (Figure 1) without a clear demarcation and displays a flattened dorsal surface facing the fundus of the internal capsule and a convex ventral surface towards the anterior perforated substance (Figure 2).
According to the anatomical study of Neto et al. [3], the anatomic boundaries of the $\mathrm{AcN}$ are the following: rostral limit : the separation of caudate/putamen from the internal capsule; caudal limit: the posterior end of the anterior commissure; internal limit: the sagittal plane passing by the ventral tip of the frontal horn of the lateral ventricle; external limit: a vertical line extending downwards and laterally the rostral edge of the internal capsule; ventral limit: the external capsule and Broca's diagonal band; dorsal limit: the horizontal plane passing from the inferior border of the anterior horn of the lateral ventricle to the inferior limit of the internal capsule. 


\section{Medical Imaging}
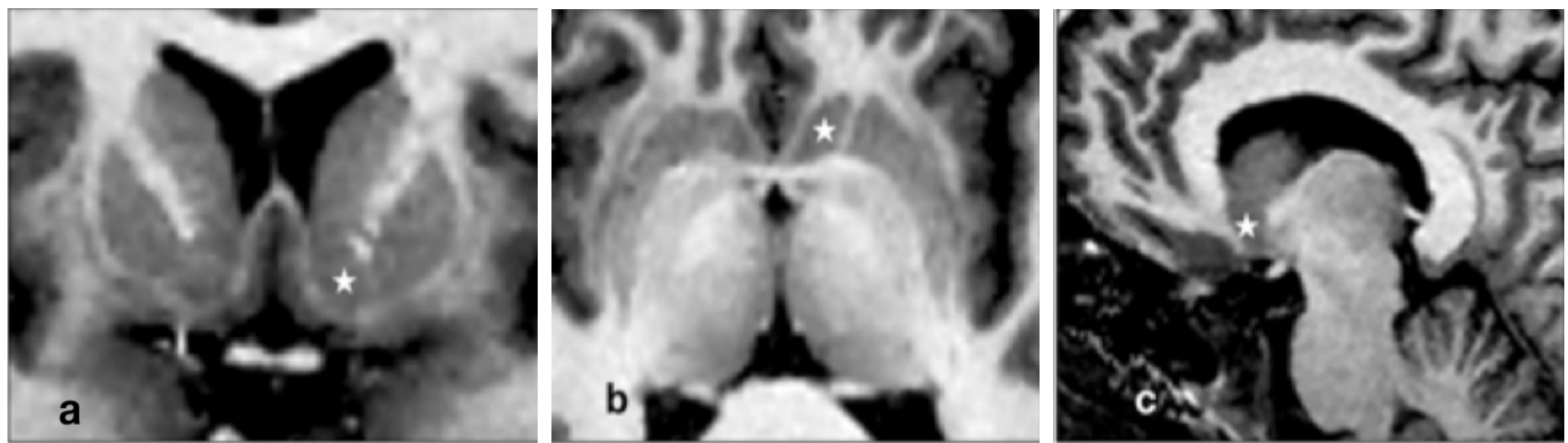

Figure 1. The AcN in coronal (a), axial (b) and sagittal (c) plane.
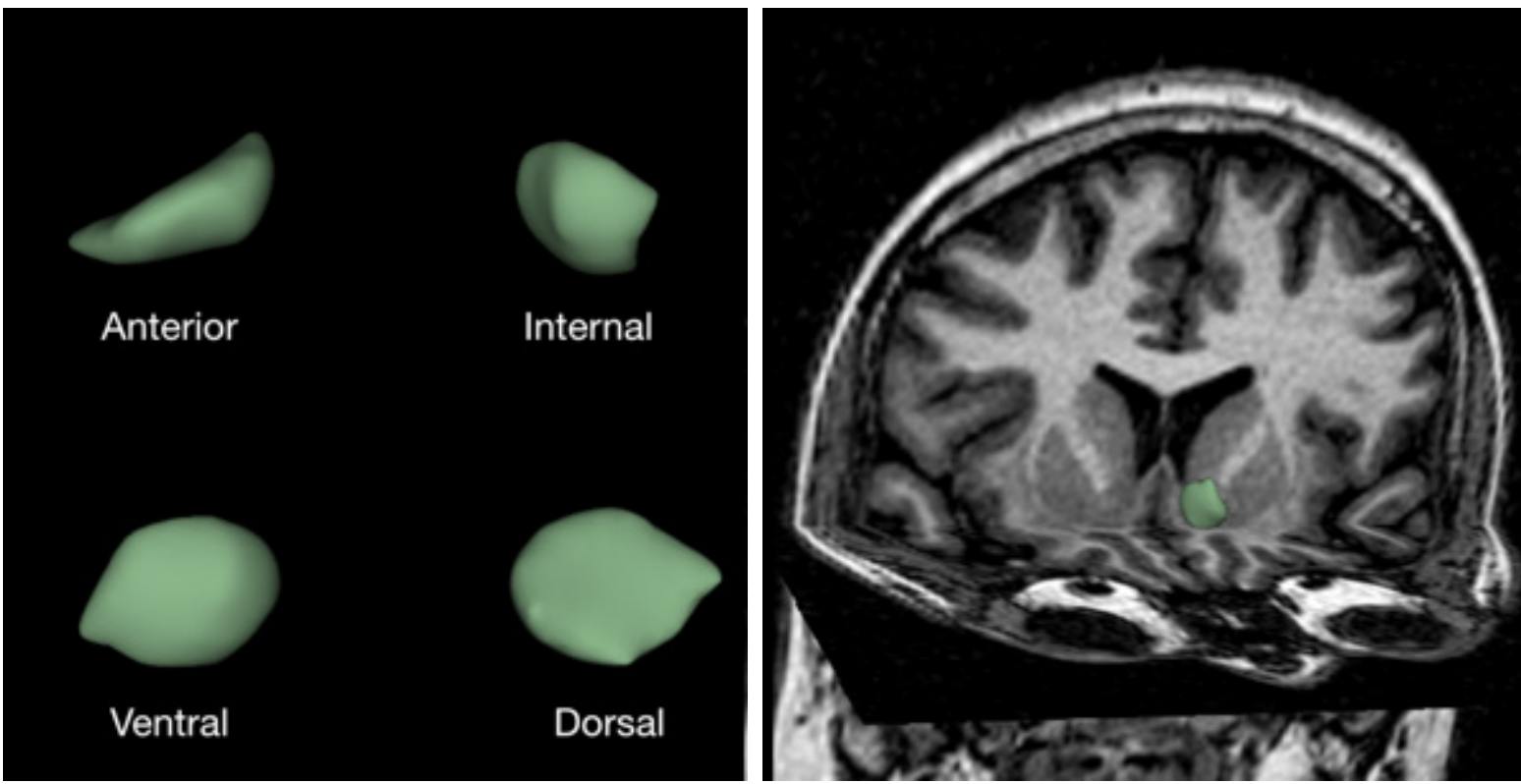

Figure 2. 3D volume renderings of the $\mathrm{AcN}$.

In immunochemistry studies, the AcN is divided into two parts: a shell, related to the limbic system and a core related to the extrapyramidal system $[2,4]$. The AcN receives dopaminergic fibers from the substantia nigra and from the ventral tegmental area (VTA), through the mesolimbic pathway, as well as glutamatergic projections from the subiculum, amygdala, hippocampus and prefrontal cortex. The most important efferent pathway is GABAergic and terminates in the ventral pallidum. The other efferent connections concern the mediodorsal thalamus, the dorsal striatum, the lateral habenular nucleus, the lateral hypothalamus, the substantia nigra, the ventral tegmental area, as well as the rostral part of the cingulate gyrus $[1,5,6]$. Due to the strong connections with the structures of the limbic system and the projections towards the dorsal striatum, the AcN constitutes a relay stage between the limbic and the extrapyramidal system and is involved in several neuropsychiatric disorders, such as Parkinson's disease [7], Alzheimer's disease [8,9], Huntington's chorea [10], schizophrenia [11,12] and drug addiction $[13,14,15]$, in which morphometric alterations have been observed. The prior knowledge of normal volumetric data constitutes an essential precondition for the evaluation of alterations that occur in various pathological conditions.

The purpose of our study was to estimate the normal AcN volume from a large number of manually segmented MRI scans and to analyze the resulting volumes for differences related to hemisphere, sex and age. 


\section{Methods \\ Subjects}

For this study we have used a previously described brain MRI data set [16], consisting of 106 MRI scans of healthy adults (39 men, 67 women, aged between 18 and 80 years, average age: 38.6 years). The study was realized with the approval of the medical ethic commission of the Democritus University of Thrace Medical School.

\section{MRI acquisition and imaging post-processing}

All subjects were scanned on a 1.5 Tesla MRI scanner (Intera; Philips Medical Systems, Best, The Netherlands) with a standard head coil. The structural scans have been acquired using a sagittal T1 3D Turbo Field Echo sequence $\left(\mathrm{TR} / \mathrm{TE}=9.3 / 3.1 \mathrm{msec}\right.$, flip angle $=8^{\circ}, \mathrm{FOV}=256$ $\mathrm{mm}$, matrix $=256 \mathrm{X} 204$, slice thickness $=1 \mathrm{~mm}$, total scan time $=13 \mathrm{~min}$ ). The MRI data sets have been transferred to a Mackintosh unit (OS X 10.8.3 3.2 GHz Intel Core i5, 16 GB RAM, 27-inch, retina 5K) for segmentation and volumetric measurements using the 3D SLICER software package (Brigham and Women's Hospital Harvard Medical School, MIT, USA) [17]. Prior to AcN segmentation, the axial slices were realigned using the intercommissural line (AC/PC line) and the mid sagittal plane in order to eliminate variations of the head position between MRI scans. For bias field correction, we have used the algorithm N4ITK MRI BIAS CORRECTION [18] and an anisotropic diffusion filter was applied for noise reduction and edge enhancement [19]. In order to normalize the results, we have measured the intracranial volume (ICV) using the automatic EMSegmenter with atlas tool as previously described [20].

\section{Anatomic boundaries}

The tracing of the AcN boundaries was based on a previous segmentation protocol by Laboratory of Neuroimaging, UCLA (LONI) [21] with a minor modification in the demarcation of its rostral end, which was placed in the first coronal reformation, where the putamen and the head of the caudate nucleus appear simultaneously (Figure 3). This modification was made in order to include in the measurements the $\mathrm{AcN}$ part which is located ventrally to the head of the caudate nucleus according to the Atlas of the Human Brain by Mai et al. [22] and is proposed by the Center for Morphometric Analysis (CMA) at Massachusetts General Hospital, Harvard Medical School [23].

The regions of interest (ROI's) were drawn in coronal reformations with constant reference to the other two orthogonal planes in the following way:

The rostral end is dorsally separated from the head of the caudate nucleus, drawing an oblique line that is extended from the inferior tip of the frontal horn of the lateral ventricle to the internal capsule, in an imaginary continuation with the inferior most tip of the putamen (Figure 3).

The ventromedial border is delineated by the white matter of the septal area as well as by the vertical limb of Broca's diagonal band and the ventrolateral border by the external capsule (Figure 4).

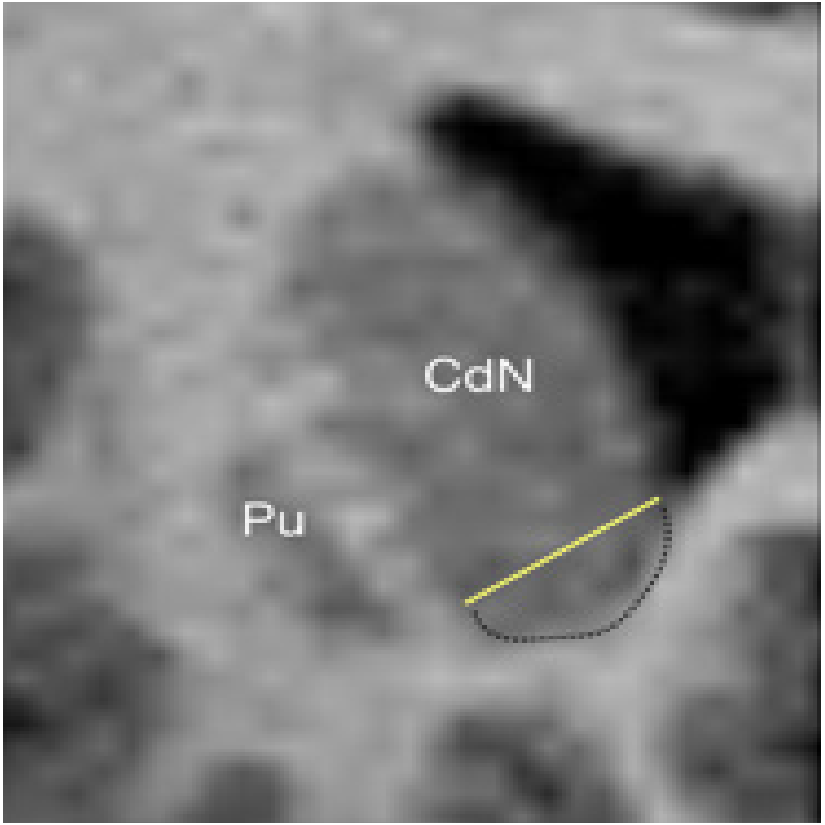

Figure 3. The upper border of the rostral end of the AcN. Abbreviations: $\mathrm{CdN}$ - caudate nucleus, $\mathrm{Pu}$ - putamen.

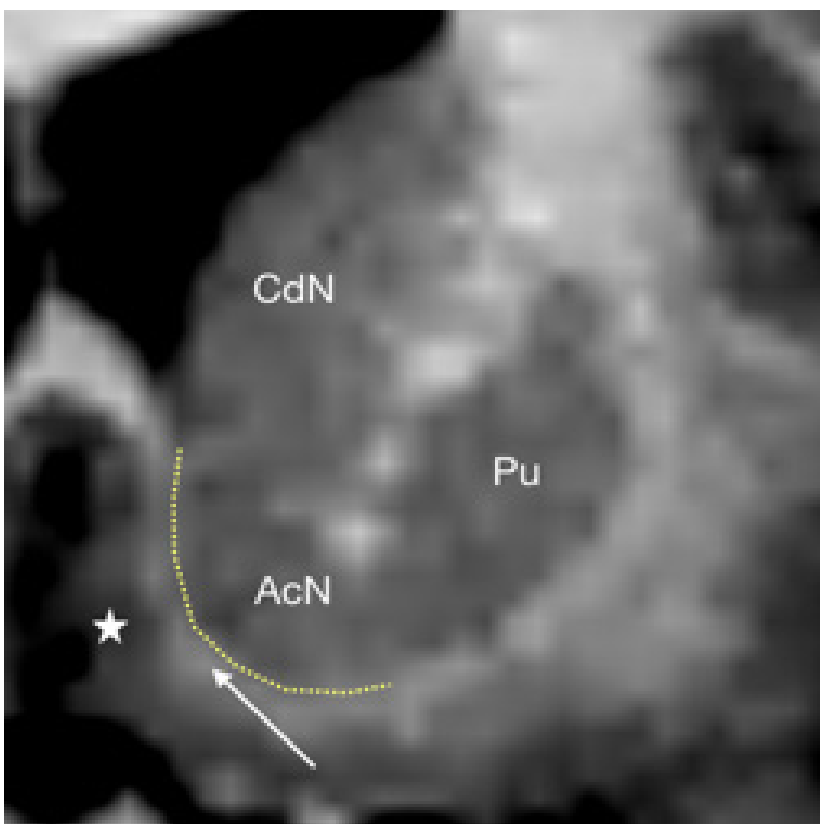

Figure 4. The ventromedial and ventrolateral border of the AcN. Abbreviations: $\mathrm{CdN}$ - caudate nucleus, $\mathrm{Pu}$ - putamen. With asterisk the septal area and with arrow Broca's diagonal band.

In the slices before the appearance of the globus pallidus, the upper border is defined by a line that connects the inferior tip of the frontal horn of the lateral ventricle with the inferior part of the internal capsule. After the appearance of the globus pallidus, the above-mentioned line heads towards the inferior part of the external medullary lamina (Figure 5). 

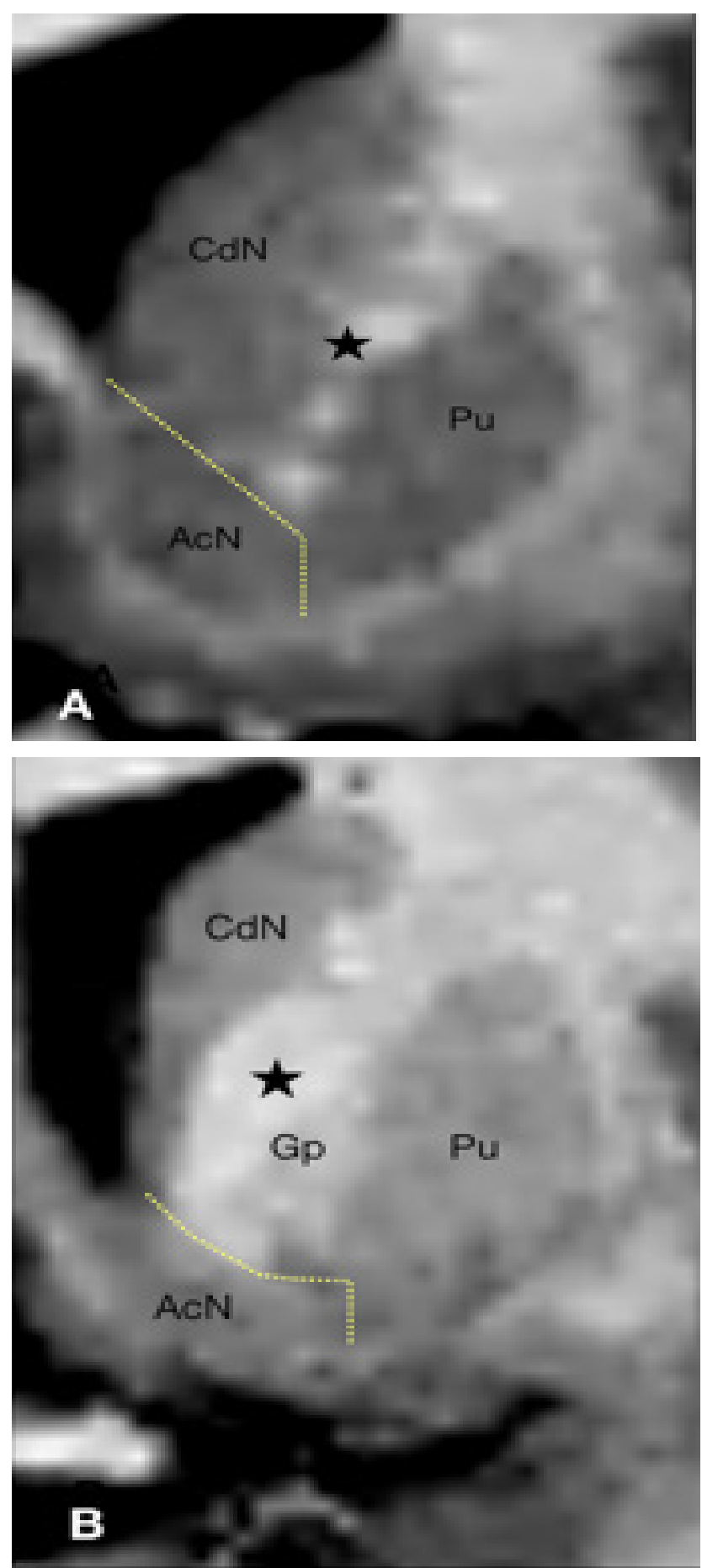

Figure 5. The dorsal and lateral border before (A) and after (B) the appearance of the globus pallidus. $\mathrm{CdN}$-caudate nucleus, $\mathrm{Gp}$ - globus pallidus, $\mathrm{Pu}$ - putamen. With asterisk the internal capsule.

According to the slice (before or after the appearance of the globus pallidus), the outer border is defined by a line vertical to the white matter of the basal forebrain, passing through the inferior most tip of the internal capsule or, correspondingly, through the inferior most tip of the external medullary lamina (Figure 5).
The caudal end of the AcN corresponds to the coronal reformation which displays the decussation of the anterior commissure and it is enclosed within an oval ROI, which is extended from the external medullary lamina to the plane of the frontal horn of the lateral ventricle (Figure 6).

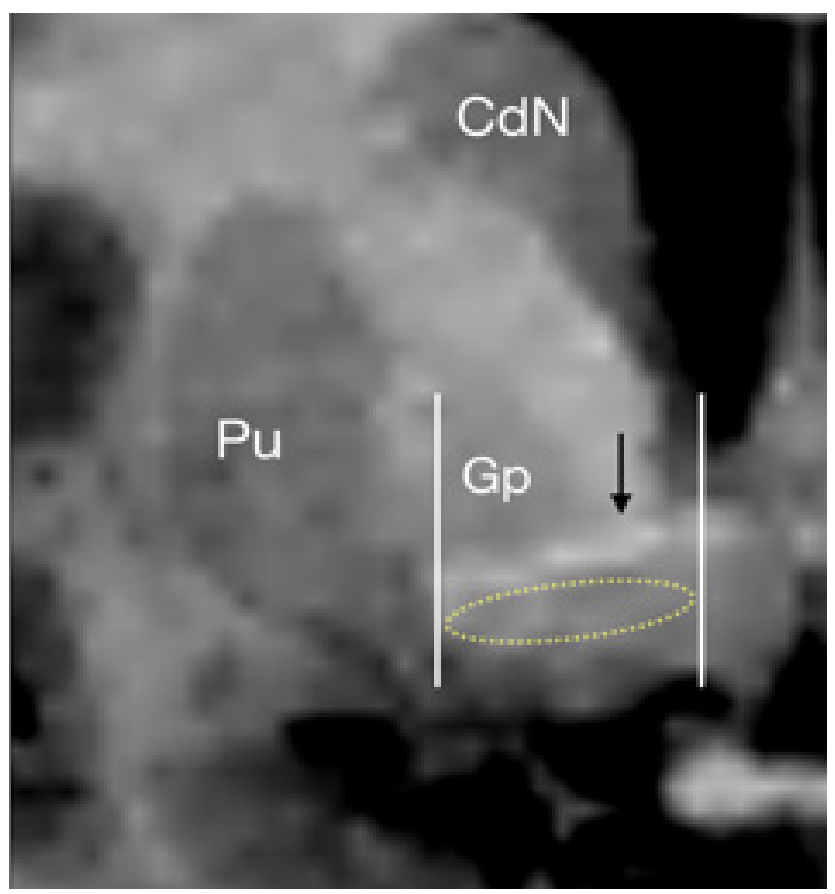

Figure 6. The caudal end of the AcN. Abbreviations: CdN caudate nucleus, $\mathrm{Gp}$ - globus pallidus, $\mathrm{Pu}$ - putamen.

\section{Statistical analysis and results}

The analysis was performed with IBM Statistics SPSS 21 and the statistical significance was set at $\mathrm{p}<0.05$.

Normality of the data has been tested with the Kolmogorov-Smirnov test and the Levene's test has been employed to check homogeneity of variance between groups. In order to compensate gender and inter-subject differences due to head size, the raw volumes were normalized by dividing each raw volume with the corresponding ICV. A 2 X2 analysis of the variance model with repeated measurements has been used to compare total mean volumes between right and left AcN, as well as to estimate the effect of gender. The association between the right and left $\mathrm{AcN}$ volumes and the association between the volumes and age, in the total sample or regarding sex has been estimated with the Pearson's correlation coefficient. The algorithm CURVEFIT was used to estimate non-linear relationships between the volumes (raw/normalized) and age. Moreover, the directed index of interhemispheric asymmetry (DIHA) was calculated with formula: $100 \%$ [(right volume - left volume) / 0.5 (right volume + left volume) ] and was associated with age regarding or not sex $[16,24]$. Finally, the effect of age and age 2 on the differences between the right and left $\mathrm{AcN}$ volumes was analyzed with a linear mixed model (SPSS algorithm MIXED). 
Table I. Descriptive statistics of raw AcN volumes.

\begin{tabular}{|c|c|c|c|c|c|c|c|}
\hline Volumetrics & Sex & Minimum & Maximum & Mean & SD & Median & $\begin{array}{c}\text { Coefficient of } \\
\text { Variation (\%) }\end{array}$ \\
\hline \multirow{3}{*}{$\mathrm{RAcN}$} & $\mathrm{M}(\mathrm{N}=39)$ & 335 & 719 & 536.51 & 107.12 & 534 & 20.0 \\
\hline & $\mathrm{F}(\mathrm{N}=67)$ & 278 & 633 & 429 & 83.53 & 437 & 19.5 \\
\hline & Total $(\mathrm{N}=106)$ & 278 & 719 & 468.56 & 106.08 & 455 & 22.6 \\
\hline \multirow{3}{*}{$\mathrm{LAcN}$} & $\mathrm{M}(\mathrm{N}=39)$ & 310 & 731 & 551.38 & 106.55 & 561 & 19.3 \\
\hline & $\mathrm{F}(\mathrm{N}=67)$ & 276 & 630 & 435.36 & 83.43 & 432 & 19.2 \\
\hline & Total $(\mathrm{N}=106)$ & 276 & 731 & 478.05 & 107.91 & 473 & 22.6 \\
\hline
\end{tabular}

\section{Reliability and method error}

From the study dataset, 22 MRI scans were selected at random and the $\mathrm{AcN}$ volumes remeasured by the main author after a 2 - week interval. The intra-rater reliability for the right and left $\mathrm{AcN}$ volumes was validated with the intraclass correlation coefficient (ICC). Moreover, the Bland-Altman method was used to estimate the method error and to evaluate statistically significant differences that might emerge from the study. Results are presented in the following section.

\section{Volumetrics}

The intraclass correlation coefficient for the right AcN was 0.924 (95\% CI: 0.828 - 0.967) and for the left AcN was 0.923 (95\% CI: 0.826 - 0.967). Regarding method error, the mean difference for the right $\mathrm{AcN}$ was $5.9 \mathrm{~mm}^{3}$ and the limits of disagreement were estimated from -66.3 to $54.6 \mathrm{~mm}^{3}$, while for the left AcN the mean difference was $4.2 \mathrm{~mm}^{3}$ and the limits of disagreement were estimated from -71.3 to $62.8 \mathrm{~mm}^{3}$. Hence, significant statistically mean differences greater than $67 \mathrm{~mm}^{3}$ are considered as non-random and reliable.

\section{Raw volumes}

Concerning hemisphere and sex, data were normally distributed and the results of the Levene's test of homogeneity of variances were not statistically significant. The mean raw AcN volume was $473.3 \mathrm{~mm}^{3}(\mathrm{SD}= \pm 106.8)$. Descriptive statistics about raw volumes are given in Table I.

A strong positive statistically significant correlation was found between the total right and left raw AcN volumes (Pearson's $r=0.971, \mathrm{p}<0.001$ ) regardless of gender (males: Pearson's $\mathrm{r}=0.970, \mathrm{p}<0.001$, females: Pearson's $\mathrm{r}=0.972, \mathrm{p}<0.001$ ) (Fig. 7). The mean raw volume in both hemispheres was not significantly different between sexes (right: $\mathrm{F}(1,104)=2.963, \mathrm{p}=0.088$, estimated mean difference $=36.4, \mathrm{SE}=103$, left: $\mathrm{F}(1,104)=2.077, \mathrm{p}=0.153$, estimated mean difference $=31.2, \mathrm{SE}=96.1$ ).

In the total sample the mean left raw $\mathrm{AcN}$ volume was greater than the right, but the difference was less than $67 \mathrm{~mm}^{3}(\mathrm{~F}(1,104)=11.595, \mathrm{p}=0.001$, estimated mean difference $=8.8, \mathrm{SE}=2.6$ ). Moreover, no statistically significant interaction has been found between gender and hemisphere $(\mathrm{F}(1,104)=1.045, \mathrm{p}=0.309$, estimated mean difference in males $=6.2, \mathrm{SE}=4.1$, estimated mean difference in females $=11.4, \mathrm{SE}=3.1$ ).
We found a statistically significant negative correlation between raw volumes and age in males (Pearson's $\mathrm{r}=-0.416$ between age and right $\mathrm{AcN}, \mathrm{p}=0.008$ and Pearson's $r=-0.356$, between age and left $A c N, p=0.026$ ) while in females or in the total sample no linear correlation have been observed (females: Pearson's $r=0.062$ between age and right $A c N, p=0.617$ and Pearson's $r=0.032$, between age and left AcN, $\mathrm{p}=0.796$, total sample: Pearson's $\mathrm{r}=-0.111$ between age and right $\mathrm{AcN}, \mathrm{p}=0.256$ and Pearson's $\mathrm{r}=-0.113$, between age and left AcN, $\mathrm{p}=0.248$ ) (Figures 8,9). Finally, no non-linear relationship was found between raw volumes and age regarding or not sex.

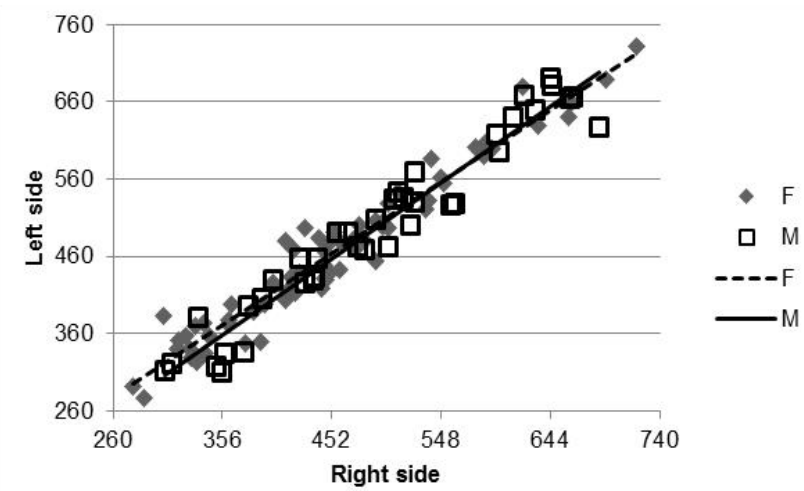

Figure 7. Relationship between the raw volumes of the right and left $\mathrm{AcN}$ according to sex $\left(\mathrm{mm}^{3}\right)$.

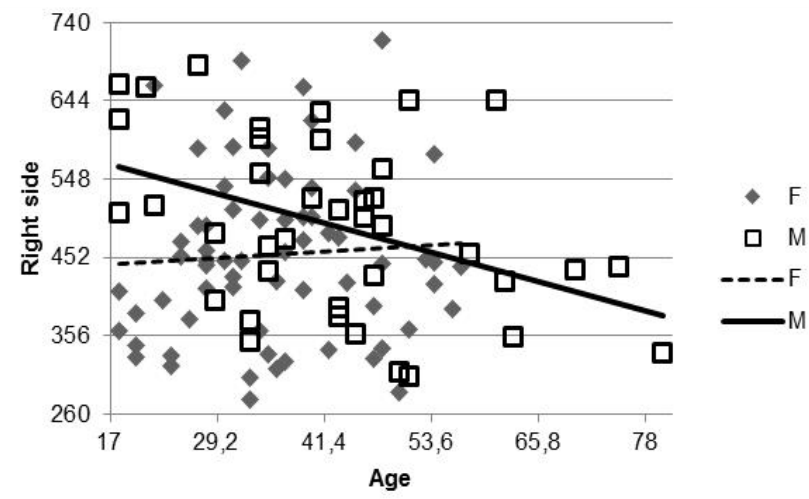

Figure 8. Relationship between age and right $\mathrm{AcN}$ raw volumes by $\operatorname{sex}\left(\mathrm{mm}^{3}\right)$. 
Table II. Descriptive statistics of normalized AcN volumes.

\begin{tabular}{rl|c|c|c|c|cc} 
Volumetrics & \multicolumn{1}{c|}{ Sex } & Minimum & Maximum & Mean & SD & Median & $\begin{array}{c}\text { Coefficient of } \\
\text { Variation (\%) }\end{array}$ \\
\cline { 3 - 9 } RAcN & $\mathrm{M}(\mathrm{N}=39)$ & 0.0002053 & 0.0004932 & 0.0003585 & 0.0000633 & 0.0003619 & 17.7 \\
& $\mathrm{~F}(\mathrm{~N}=67)$ & 0.0001770 & 0.0004968 & 0.0002918 & 0.0000629 & 0.0002910 & 21.6 \\
& Total $(\mathrm{N}=106)$ & 0.0001770 & 0.0004968 & 0.0003163 & 0.0000706 & 0.0003141 & 22.3 \\
\multirow{3}{*}{ LAcN } & $\mathrm{M}(\mathrm{N}=39)$ & 0.0002033 & 0.0004896 & 0.0003687 & 0.0000638 & 0.0003694 & 17.3 \\
& $\mathrm{~F}(\mathrm{~N}=67)$ & 0.0001785 & 0.0004944 & 0.0002959 & 0.0000626 & 0.0002949 & 21.2 \\
& Total $(\mathrm{N}=106)$ & 0.0001785 & 0.0004944 & 0.0003227 & 0.0000720 & 0.0003239 & 22.3
\end{tabular}

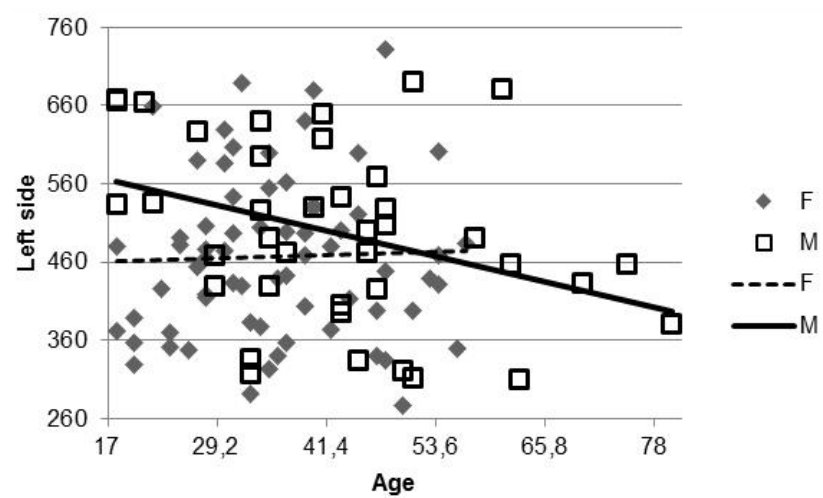

Figure 9. Relationship between age and left $\mathrm{AcN}$ raw volumes by $\operatorname{sex}\left(\mathrm{mm}^{3}\right)$.

\section{Normalized volumes}

The mean normalized $\mathrm{AcN}$ volume was 0.00032 $\mathrm{mm}^{3} \quad(\mathrm{SD}= \pm 0.00007)$. Descriptive statistics about normalized volumes are given in Table II.

A strong positive statistically significant correlation was found between total right and left normalized $\mathrm{AcN}$ volumes (Pearson's $r=0.971, p<0.001$ ) regardless of gender (males: Pearson's $\mathrm{r}=0.971, \mathrm{p}<0.001$, females: Pearson's $r=0.973, p<0.001$ ) (Figure 10).

The mean right and left normalized volumes were not significantly different between males and females $(F(1,104)=0.871, p=0.535$ for the right side and $\mathrm{F}(1,104)=1.415, \mathrm{p}=0.231$ for the left side). In the total sample the mean left normalized volume was larger than the right $(\mathrm{F}(1,104)=11.454, \mathrm{p}=0.001$, estimated mean difference $=0.0000058, \mathrm{SE}=0.000002$ ). No significant interaction was found between gender and hemisphere $(\mathrm{F}(1,104)=1.451, \mathrm{p}=0.231$, estimated mean difference for males $=0.0000037, \mathrm{SE}=0.0000027$, estimated mean difference for females $=0.0000079, \mathrm{SE}=0.0000021$ ).

As in the case of the raw volumes we found a negative correlation between normalized volumes and age in males (Pearson's $r=-0.450$ between age and right
$A c N, p=0.004$ and Pearson's $r=-0.391$, between left $A c N$, $\mathrm{p}=0.014$ ), while in females or in the total sample no linear correlation have been observed (females: Pearson's r= 0.081 between age and right $\mathrm{AcN}, \mathrm{p}=0.513$ and Pearson's $\mathrm{r}=0.053$, between age and left AcN, $\mathrm{p}=0.670$, total sample: Pearson's $r=-0.168$ between age and right $\mathrm{AcN}$, $\mathrm{p}=0.085$ and Pearson's $\mathrm{r}=-0.173$, between age and left $\mathrm{AcN}, \mathrm{p}=0.076$ ) (Figures 11, 12).

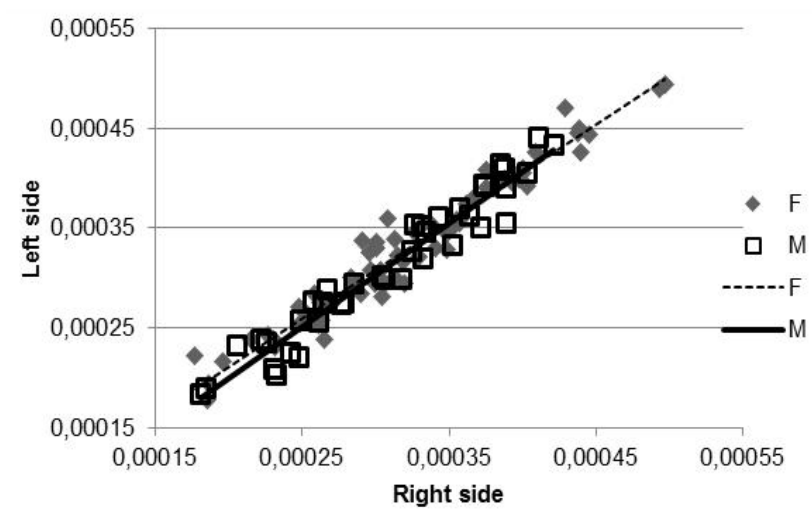

Figure 10. Relationship between the normalized volumes of the right and left $\mathrm{AcN}$ according to sex $\left(\mathrm{mm}^{3}\right)$.

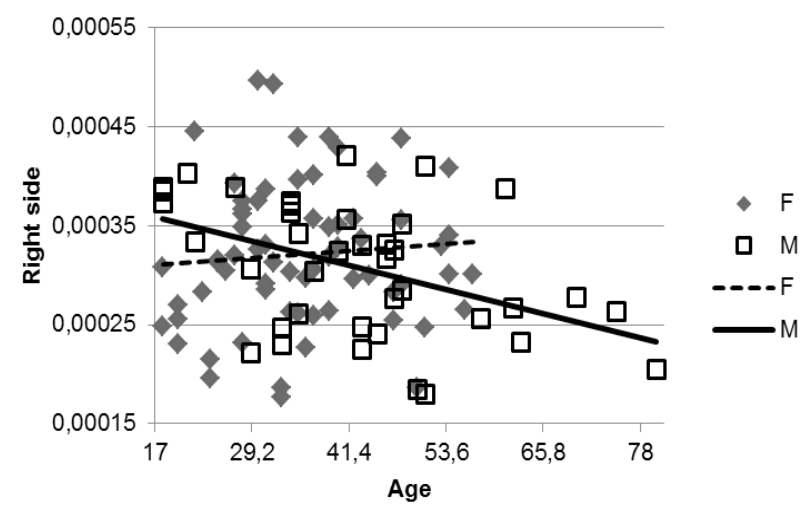

Figure 11. Relationship between right $\mathrm{AcN}$ normalized volumes and age by sex $\left(\mathrm{mm}^{3}\right)$. 
Table III. Descriptive statistics of DIHA.

\begin{tabular}{rl|c|c|c|c|c|c} 
Volumetrics & \multicolumn{1}{c|}{ Sex } & Minimum & Maximum & Mean & SD & Median & $\begin{array}{c}\text { Coefficient of } \\
\text { Variation (\%) }\end{array}$ \\
\cline { 3 - 9 } RAcN & $\mathrm{M}(\mathrm{N}=39)$ & 0.0002053 & 0.0004932 & 0.0003585 & 0.0000633 & 0.0003619 & 17.7 \\
& $\mathrm{~F}(\mathrm{~N}=67)$ & 0.0001770 & 0.0004968 & 0.0002918 & 0.0000629 & 0.0002910 & 21.6 \\
& Total $(\mathrm{N}=106)$ & 0.0001770 & 0.0004968 & 0.0003163 & 0.0000706 & 0.0003141 & 22.3 \\
\multirow{3}{*}{ LAcN } & $\mathrm{M}(\mathrm{N}=39)$ & 0.0002033 & 0.0004896 & 0.0003687 & 0.0000638 & 0.0003694 & 17.3 \\
& $\mathrm{~F}(\mathrm{~N}=67)$ & 0.0001785 & 0.0004944 & 0.0002959 & 0.0000626 & 0.0002949 & 21.2 \\
& Total $(\mathrm{N}=106)$ & 0.0001785 & 0.0004944 & 0.0003227 & 0.0000720 & 0.0003239 & 22.3
\end{tabular}

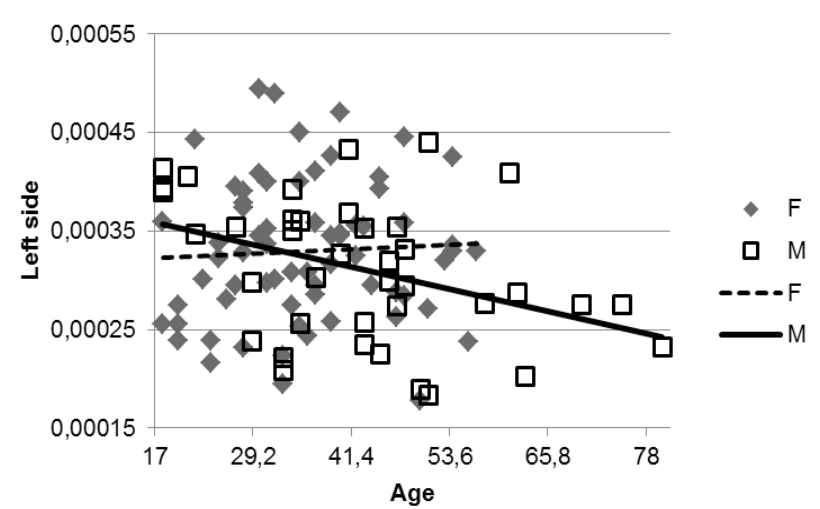

Figure 12. Relationship between left AcN normalized volumes and age by sex $\left(\mathrm{mm}^{3}\right)$.

\section{(DIHA) \\ Directed index of interhemispheric asymmetry}

The directed index of interhemispheric asymmetry (DIHA) values were normally distributed and descriptive statistics in total or regarding sex are presented in table III. No linear or non-linear relationships were observed between DIHA and age. volumes

The effect of age on raw and normalized AcN

No significant effect of age on raw or normalized $\mathrm{AcN}$ volumes was observed. In the linear mixed models that used, the covariates age and age ${ }^{2}$, these were not statistically significant for both raw (age: $\mathrm{F}(1,102)=0.667$, $\mathrm{p}=0.416$, age $\left.\mathrm{e}^{2} \mathrm{~F}(1,102)=1.450, \mathrm{p}=0.231\right)$ and normalized volumes (age: $\mathrm{F}(1,1147.348)=0.919, \mathrm{p}=0.338$, age ${ }^{2}: \mathrm{F}(1$, $1147.348)=1.758, \mathrm{p}=0.185)$.

\section{Discussion}

The AcN, functionally inserted between the limbic system and motor mechanism, is involved in the pathophysiology of several neurodegenerative and psychiatric disorders and, over the last decade, it is attracting growing attention from the scientific community [3], especially in the field of deep brain stimulation
(DBS) in which the estimation of its volume is essential for precise targeting [14]. Important morphometric AcN analysis includes the studies of Neto et al. [3] and Mavridis et al. [25] that estimate AcN dimensions: in the first case in 12 human cadaver brains with MRI scans and anatomical coronal serial cuts and in the second in 18 normal brain specimens and in 26 MRI scans deriving from neurosurgical patients. As far as the imaging volumetric studies are concerned, and in comparison with the dorsal striatum, these are considerably fewer and the majority of them were performed in the context of comparative assessment of its volume in diverse pathological conditions, using a limited number of healthy controls $[11,26,27]$. In this context, the overall study objective was to investigate the normal volumetric data from a large number of manually segmented MRI scans and, more specifically, to estimate the mean raw and normalized volumes, showcase the differences between hemispheres along with gender differences and to examine the relationship between the volumes and age.

The mean raw AcN volume was $473.3 \mathrm{~mm}^{3}$ $(\mathrm{SD}= \pm 106.8)$ and the normalized mean was $0.00032 \mathrm{~mm}^{3}$ ( $\mathrm{SD}= \pm 0.00007)$. A slight leftward asymmetry was noted, which accords with a previous imaging study including 30 MRI scans [28]. Nevertheless, it should be mentioned that the value of this difference was within the limits of the method error and needs to be further examined with larger population samples. In prior morphometric studies, the $\mathrm{AcN}$ is presented as a symmetric structure, e.g. studies of Mavridis at al. [25] and Brabec et al. [29], despite the fact that the latter have studied the combined caudate/ $\mathrm{AcN}$ volume. In contrast, Neto et al. indicate that the right $\mathrm{AcN}$ is wider than the left [3].

Concerning the existence of sexual dimorphism, no difference between genders was found either in raw or normalized volumes, which is in accordance with previous imaging and anatomical studies [25,29]. A statistically significant negative correlation between the $\mathrm{AcN}$ volumes and age was found only in males, while in females or in the total sample no correlation was 
found. Moreover, there was no non-linear relationship regarding age. Decline of the $\mathrm{AcN}$ volume relating to age is mentioned by Jernigan et al. and Walhovd et al. [30,31], whereas Neto et al. [3] and Mavridis et al. [25] found no age-related changes in its dimensions. Finally, no linear or non-linear relationship between the slight leftward asymmetry and age was found.

\section{Conclusions}

Conclusively, our study provides normal AcN volumetric data derived from a quite large number of manually segmented MRI scans, useful as a benchmark in the study of alterations that accompany various neurological and psychiatric disorders.

\section{References}

1. Salgado S, Kaplitt MG. The Nucleus Accumbens: A Comprehensive Review. Stereotact Funct Neurosurg. 2015;93:75-93.

2. Heimer L. Basal forebrain in the context of schizophrenia. Brain Res Brain Res Rev. 2000;31:205-235.

3. Neto LL, Oliveira E, Correia F, Ferreira AG. The human nucleus accumbens: where is it? A stereotactic, anatomical and magnetic resonance imaging study. Neuromodulation. 2008;11:13-22.

4. Voorn P, Brady LS, Schotte A, Berendse HW, Richfield EK. Evidence for two neurochemical divisions in the human nucleus accumbens. Eur J Neurosci. 1994;6:1913-1916.

5. Nauta WJ, Smith GP, Faull RL, Domesick VB. Efferent connections and nigral afferents of the nucleus accumbens septi in the rat. Neuroscience. 1978;3:385-401.

6. Swanson LW, Cwan WM. A note on the connections and development of the nucleus accumbens. Brain Res. 1975;92:324-330.

7. Mavridis I, Boviatsis E, Anagnostopoulou S. The human nucleus accumbens suffers parkinsonism-related shrinkage: a novel finding. Surg Radiol Anat. 2011;33:595-599.

8. Nie X, Sun Y, Wan S, Zhao H, Liu R, Li X, et al. Subregional Structural Alterations in Hippocampus and Nucleus Accumbens Correlate with the Clinical Impairment in Patients with Alzheimer's Disease Clinical Spectrum: Parallel Combining Volume and Vertex-Based Approach. Front Neurol. 2017;8:399.

9. Pievani M, Bocchetta M, Boccardi M, Cavedo E, Bonetti M, Thompson PM, et al. Striatal morphology in early-onset and late-onset Alzheimer's disease: a preliminary study. Neurobiol Aging. 2013;34:1728-1739.

10. van der Bogaard SJ, Dumas EM, Acharya TP Johnson H, Langbehn DR, Scahill RI, et al. Early atrophy of pallidum and accumbens nucleus in Huntington's disease. J Neurol. 2011;258:412-420.

11. Lauer M, Senitz D, Beckmann H. Increased volume of the nucleus accumbens in schizophrenia. J Neural Transm (Vienna). 2001;108:645-660.
12. Bois C, Levita L, Ripp I, Owens DC, Johnstone EC, Whalley $\mathrm{HC}$, et al. Hippocampal, amygdala and nucleus accumbens volume in first-episode schizophrenia patients and individuals at high familial risk: A cross-sectional comparison. Schizophr Res. 2015;165:45-51.

13. Thayer RE, Crotwell SM, Callahan TJ, Hutchison KE, Bryan AD. Nucleus Accumbens Volume Is Associated with Frequency of Alcohol Use among Juvenile Justice-Involved Adolescents. Brain Sci 2012;2:605-618.

14. Müller UJ, Truebner K, Schiltz K, Kuhn J, Mawrin C, Dobrowolny $\mathrm{H}$, et al. Postmortem volumetric analysis of the nucleus accumbens in male heroin addicts: implications for deep brain stimulation. Eur Arch Psychiatry Clin Neurosci. 2015;265:647-653.

15. Seifert CL, Magon S, Sprenger T, Lang UE, Huber CG, Denier N, et al. Reduced volume of the nucleus accumbens in heroin addiction. Eur Arch Psychiatry Clin Neurosci. 2015;265:637-645.

16. Siozopoulos A, Thomaidis V, Prassopoulos P, Fiska A. In vivo estimation of normal amygdala volume from structural MRI scans with anatomical-based segmentation. Surg Radiol Anat. 2018;40:145-157.

17. Fedorov A, Beichel R, Kalpathy-Cramer J, Finet J, FillionRobin JC, Pujol S, et al. 3D Slicer as an image computing platform for the Quantitative Imaging Network. Magn Reson Imaging. 2012;30:1323-1341.

18. Sled JG, Zijdenbos AP, Evans AC. A nonparametric method for automatic correction of intensity nonuniformity in MRI data. IEEE Trans Med Imaging. 1998;17:87-97.

19. Gerig G, Kubler O, Kikinis R, Jolesz FA. Nonlinear anisotropic filtering of MRI data. IEEE Trans Med Imaging. 1992;11:221-232.

20. Pohl KM, Bouix S, Nakamura M, Rohlfing T, McCarley RW, Kikinis R, et al. A hierarchical algorithm for MR brain image parcellation. IEEE Trans Med Imaging. 2007;26:1201-1212.

21. Ballmaier M, Toga AW, Siddarth P, Blanton RE, Levitt JG, Lee $\mathrm{M}$, et al. Thought disorder and nucleus accumbens in childhood: a structural MRI study. Psychiatry Res. 2004;130:43-55.

22. Mai JK, Paxinos G, Voss T. Atlas of the Human Brain. Elsevier, London 2008

23. Makris N, Meyer JW, Bates JF, Yeterian EH, Kennedy DN, Caviness VS. MRI-Based topographic parcellation of human cerebral white matter and nuclei II. Rationale and applications with systematics of cerebral connectivity. Neuroimage. 1999;9:18-45.

24. Brabec J, Rulseh A, Hoyt B, Vizek M, Horinek D, Hort J, et al. Volumetry of the human amygdala - an anatomical study. Psychiatry Res. 2010;182:67-72.

25. Mavridis I, Boviatsis E, Anagnostopoulou S. Anatomy of the human nucleus accumbens: a combined morphometric study. Surg Radiol Anat. 2011;33:405-414.

26. Coutinho J, Ramos AF, Maia L, Castro L, Conceição E, Geliebter A, et al. Volumetric alterations in the nucleus accumbens and caudate nucleus in bulimia nervosa: a 
structural magnetic resonance imaging study. Int $\mathrm{J}$ Eat Disord 2015;48:206-214.

27. Levitt JJ, Rosow LK, Nestor PG, Pelavin PE, Swisher TM, McCarley RW, et al. A volumetric MRI study of limbic, associative and sensorimotor striatal subregions in schizophrenia. Schizophr Res. 2013;145:11-19.

28. Ahsan RL, Allom R, Gousias IS, Habib H, Turkheimer FE, Free S, et al. Volumes, spatial extents and a probabilistic atlas of the human basal ganglia and thalamus. Neuroimage. 2007;38:261-270.
29. Brabec J, Krásený J, Petrovický P. Volumetry of striatum and pallidum in man--anatomy, cytoarchitecture, connections, MRI and aging. Sb Lek. 2003;104:13-65.

30. Jernigan TL, Archibald SL, Fennema-Notestine C, Gamst AC, Stout JC, Bonner J, et al. Effects of age on tissues and regions of the cerebrum and cerebellum. Neurobiol Aging. 2001;22:581-594.

31. Walhovd KB, Fjell AM, Reinvang I, Lundervold A, Dale AM, Eilertsen DE, et al. Effects of age on volumes of cortex, white matter and subcortical structures. Neurobiol Aging. 2005;26:1261-1270. 